\title{
Effect of Probiotic, Prebiotic and Synbiotic Supplementation on Growth Performance in Murrah Buffalo Calves
}

\author{
M. Sri Lekha ${ }^{1 *}$, Ch. Venkata Seshaiah ${ }^{2}$, P. Ashalatha ${ }^{1}$ and K. Raja Kishore ${ }^{3}$ \\ ${ }^{1}$ Department of Livestock Production Management, ${ }^{2}$ Department of Livestock Farm Complex, \\ ${ }^{3}$ Department of Animal Nutrition, NTR College of Veterinary Science, Sri Venkateswara \\ Veterinary University, Gannavaram, Andhra Pradesh-521101, India \\ *Corresponding author
}

Keywords

Murrah buffalo calves, Growth performance, multistrain probiotic,

Mannonoligosaccha ride and inulin supplementation, Synbiotic, body condition score, Cost economics

Article Info

\section{Accepted:}

12 April 2021 Available Online: 10 May 2021
In order to find out the effect of supplementation on growth performance in Murrah buffalo calves twenty four Murrah buffalo calves of about six months age were randomly divided into four groups of six calves each on the basis of body weight (BW) in a completely randomized design (CRD). Group I was set as control (C), Group-II was supplemented with multistrain probiotic containing 7 bacterial strains and 2 yeast strains $\left(2 \times 10^{9} \mathrm{cfu} / \mathrm{gm}\right)$ at $5 \mathrm{gm} / \mathrm{calf} /$ day (T1). Group-III was supplemented with prebiotic Mannonoligosaccharide + inulin at 5gm/calf/day (T2) and GroupIV was supplemented with synbiotic containing multi-strain probiotic at $2.5 \mathrm{gm}$ and $2.5 \mathrm{gms}$ of prebiotic Mannonoligosaccharide + inulin per calf/day (T3) for a period of 90 days. The present study concludes that synbiotics supplementation(T3) in buffalo calves had increased DMI, average daily gain and FCR which resulted into decreased cost of feeding per kg weight gain (₹) in buffalo calves compared to either prebiotic or probiotic supplementation alone.

\section{Introduction}

Buffalo is the back bone of Indian dairy industry contributing about $60 \%$ of total milk production in the country. Buffaloes are preferred over cattle in India because of their distinctive qualities such as better feed conversion efficiency, more resistance to diseases and higher milk fat percentage than in cows (Bandyopadhyay, et al., 2003). These animals require a relatively low level of inputs in the predominantly mixed farming systems, and are well known for their ability to thrive on low-quality crop residues and green forage 
under harsh climatic conditions (Resali, 2000). However, the mortality rate in buffalo calves particularly during first three months of their postnatal life is high, predominantly due to calf scores, causing heavy loss to the buffalo producers in India. Therefore, to combat infection, antibiotics are commonly being used as feed additives in the rations of calves.

However indiscriminate and sub-therapeutic levels of antibiotics usage in calves results in development of drug-resistant microorganisms which are responsible for treatment failures (Jin et al., 1997).

In an effort to replace antibiotics in animal feeds, many additives have been proposed as alternates to antibiotics. Probiotic, prebiotics and combination of probiotic and prebiotic Probiotics have been shown to have many function, including increasing feed efficiency and weight gain (Lesmiester et al., 2004) and improve immune system (Timmerman et al., 2005). Prebiotics are non-digestible carbohydrates which are not metabolized in the small intestine and fermented in large intestine. Recently, prebiotics have been shown to have immune-enhancing characteristics (Okomato et al., 2003; Fleige et al., 2009). Dietary inclusion of this prebiotic increased lactobacillus count and reduced $E$. coli counts in digesta of ileum, cecum and colon (Deng et al., 2007). Synbiotics are a combination of prebiotics and probiotics that benefits the host by selectively stimulating the growth or by activating the metabolism of health-promoting bacteria, and thus improving host welfare. Dietary Supplementation of synbiotics increased average daily gain and reduced fecal shedding of E.coli in calves (Roodposhti and Dabiri, 2012) and improved body weight and was affordable (Dar et al., 2017). Since there is paucity of information the present research is proposed to study the effect of synbiotic supplementation in growth performance of buffalo calves.

\section{Materials and Methods}

Twenty four Murrah buffalo calves of approximately 6 months age were selected from LFC, NTR College of Veterinary Science, Gannavaram and divided into four groups of six calves each on the basis of body weight (BW) in a completely randomized design (CRD). The average body weight (kg) in each of the groups was similar before the start of the experiment. All the experimental calves were housed with good ventilation and provision for individual feeding and watering. All the calves were fed with Hybrid Napier green fodder and concentrate mixture as basal diet as per their nutrient requirements (ICAR 2013). The calves were divided into four groups i.e. Group I as control, Group-II was supplemented with multi-strain probiotic containing 7 bacterial strains and 2 yeast strains $\left(2 \times 10^{9} \quad \mathrm{cfu} / \mathrm{gm}\right) @ 5 \mathrm{gm} / \mathrm{calf} /$ day. Group-III was supplemented with prebiotic Mannon oligosaccharide + Inulin @ $5 \mathrm{gm} /$ calf/day and Group-IV was supplemented with synbiotic containing multi-strain probiotic @2.5gm and 2.5gms of prebiotic Mannon oligosaccharide + Inulin per calf/day for a period of 90 days. All the experimental calves were dewormed and deticked using Fenbendazole @ 10mg/kg BW and Deltamethrin@4ml/L respectively before the start of the experiment. All the calves were allowed to have adaptation period for 15 days before the actual trail, during which they were fed with basal diet. After the adaptation period calves were fed with their respective treatment diets for 90 days. The diet of the experimental animals included chopped Hybrid Napier as roughage source and concentrate mixture. The ingredient composition (\%) of concentrate mixture is presented in the Table. 1. Feeding of concentrates followed by fodder was done daily in the morning and evening at a fixed time. Feed offered and feed left in the individual mangers were noted to obtain feed intake of the calf. The leftover concentrate 
mixture, if any was weighed. The indices of growth, feed intake and body condition score were taken at the beginning and every fortnight till the end of the experiment. An electronic platform weighing scale was used to record body weights. The body weights were obtained before calves were fed at the beginning of the experiment and every fortnight intervals until the end of the experiment. Bodyweight gain $(\mathrm{kg})$ was obtained by subtracting initial body weight from the final bodyweight of the experimental calf. The average daily gain (g) was calculated by subtracting the initial body weight from the final body weight and dividing it by the number of days. The cost of feeding was calculated by considering the total quantity of feed consumed by the calves during the experimental period and the price of ingredients in the local market. The body condition score was assessed by using the BCS scale developed by Alapati et al., (2010). The feed conversion ratio was calculated by dividing the total DMI (kg) by the body weight gain $(\mathrm{kg})$ of the experimental animals. The data obtained was analysed according to statistic computer program SPSS version (15.01) (SPSS, 2006).

\section{Results and Discussion}

\section{Dry Matter Intake}

The results on the effect of dietary supplementation of probiotic, prebiotic and synbiotics on dry matter intake (DMI) are presented in the Table 2. The results of the present study revealed that the DMI was significantly higher $(\mathrm{P}<0.05)$ from $45^{\text {th }}$ day of the experiment in synbiotic supplemented group compared to the probiotic, prebiotic and control groups. Compared to the control group, the DMI was significantly higher $(\mathrm{P}<0.05)$ in probiotic supplemented calves while the difference was not significant between control and prebiotic groups. The increased DMI in synbiotic supplemented group of calves might be due to better digestion and absorption of the nutrients (Moarrab et al., 2016). The results of the present study is in agreement with the findings of Kumar et al., (2011) who observed increased $(\mathrm{P}>0.05)$ dry matter intake $(\mathrm{kg} / \mathrm{d})$ in graded Murrah bull calves fed diets supplemented with probiotic yeast culture compared with the control group. Sadrsaniya et al., (2015) also observed significantly higher $(\mathrm{P}<0.05)$ average daily dry matter intake in buffaloes fed with probiotics containing yeast Saccharomyces cerevisiae and bacteria Lactobacillus sporogens. Contrary to the present results, Michael and Abney (2001) reported no significant difference in DMI between calves received probiotic and prebiotic and control group. Abdel-Fattah and Fararh (2009) also observed no significant difference in average feed intake between control and synbiotic groups in Sasso broiler chicks.

\section{Mean Body Weight}

The effect of dietary supplementation of probiotic, prebiotic and synbiotics on mean body weight gain $(\mathrm{kg})$ in buffalo calves during experimental period was presented in Table 3. The results revealed that the mean body weight gain $(\mathrm{kg})$ was significantly higher $(\mathrm{P}<0.05)$ in $\mathrm{T} 3$ group compared to the control. However significant difference was not observed in body weight gain $(\mathrm{kg})$ among $\mathrm{T} 1$, $\mathrm{T} 2$ and $\mathrm{T} 3$ groups and $\mathrm{C}, \mathrm{T} 1$ and $\mathrm{T} 2$ groups. In this study calves received a combination of probitic and prebiotic together had greater body weight gain than calves received probiotic or prebiotic alone which may be due to more synergetic effects of synbiotic on stimulating beneficial microflora compared to supplementing probiotic and prebiotic alone (Roodposhti and Dabiri., 2012). The present results are in accordance with the findings of Roodposhti and Dabiri (2012) who reported 
significantly higher $(\mathrm{P}<0.05)$ body weights in Holstein female calves supplemented with synbiotic compared to the control calves. Dar et al., (2017) and Abdel-Raheem et al., (2012) also reported significantly $(\mathrm{P}<0.05)$ higher body weight gains in calves supplemented with probiotic and synbiotic over control.

\section{Average Daily Gain}

The Average daily gain (ADG) (Kg/day) in $\mathrm{C}$, $\mathrm{T} 1, \mathrm{~T} 2$ and $\mathrm{T} 3$ during the experimental period is presented in Table 4 . The body weight gain (kg) was improved in all the experimental groups till the end of the experiment. At the end of the experiment, the average daily gain (ADG) $(\mathrm{kg} /$ day $)$ was significantly $(\mathrm{P}<0.05)$ higher in T3 group compared to the control. However significant difference was not observed in ADG among T1, T2 and T3 groups and $\mathrm{C}, \mathrm{T} 1$ and $\mathrm{T} 2$ groups. The present results were consistent with the findings of Roodposhti and Dabiri (2012) who reported that calves fed with synbiotics had higher ADG than other treatments $(\mathrm{P}<0.05)$ and there was no significant difference between probiotic and prebiotic and between probiotic and control group calves. The increased ADG in symbiotic supplemented calves might be due to synergetic effect of probiotic and prebiotic in which probiotic will help in colonization of beneficial bacteria such as Lactobacillus acidophilus and Enterococcus faecium will multiply, exclude the harmful bacteria and establish themselves in the digestive system. Further, prebiotic in the colon and large intestine act as substrate for beneficial bacteria which may result in changes in the population of beneficial microorganisms, In addition, the production of VFA by bacteria fermenting prebiotics may improve energy efficiency and alter intestinal morphology. These possible changes in the microbiology and chemistry of the large intestine may be responsible for improved ADG in calves (Roodposhti and Dabiri, 2012).

\section{Feed Conversion Ratio}

The feed conversion ratio (FCR) in $\mathrm{C}, \mathrm{T} 1, \mathrm{~T} 2$ and $\mathrm{T} 3$ during the experimental period is presented in Table 5. Statistical analysis revealed that the FCR was significantly $(\mathrm{P}<0.05)$ lower in $\mathrm{T} 3$ group compared to $\mathrm{C}, \mathrm{T} 1$ and $\mathrm{T} 2$ groups. Compared to the $\mathrm{C}$ group, the FCR was significantly lower $(\mathrm{P}<0.05)$ in $\mathrm{T} 1$ and $\mathrm{T} 2$ groups and the difference was not significant between $\mathrm{T} 1$ and $\mathrm{T} 2$ groups.

Several studies revealed that probiotics and prebiotics can improve digestibility of dry matter, energy, crude protein and amino acids (Li et al., 2008; Kong et al., 2009 and Kong et $a l ., 2011)$ and increase bioavailability of minerals in the gut which might be responsible for lowered FCR in synbiotic supplemented buffalo calves. The results of the present study are in agreement with the findings of Awad et al., (2008) who observed significantly $(\mathrm{P}<0.05) \quad$ lower FCR in synbiotics supplemented group than control and probiotic fed broilers. Abdel-Fattah and Fararh (2009) also observed lower feed conversion ratio in Sasso broilers fed with synbiotic followed by probiotic and prebiotic in comparison with the control group. Further, Kumar et al., (2011) observed increased feed efficiency in buffalo bull calves fed with probiotics and Hasunuma et al., (2011) reported increased $(\mathrm{P}<0.05)$ feed efficiency in Holstein calves fed with cellooligosaccharide than in the control group.

\section{Body Condition Score}

The results of effect of dietary supplementation of probiotic, prebiotic and synbiotics on BCS are presented in Table 6. The present study revealed that BCS was not significantly different among the experimental groups. Berry et al., (2006) revealed that the average change in body weight per unit change in BCS (scale of 1 to 10) was $31 \mathrm{~kg}$ in cattle. 
Table.1 Ingredient composition of concentrate feed used for experimental calves

\begin{tabular}{|c|c|}
\hline Ingredients & Parts (100) \\
\hline Maize & 40 \\
\hline $\begin{array}{c}\text { De-oiled rice bran } \\
\text { (DORB) }\end{array}$ & 18 \\
\hline Soybean meal & 30 \\
\hline Ground Nut cake & 5 \\
\hline Molasses & 4 \\
\hline Di-Calcium Phosphate & 2 \\
\hline Salt & 1 \\
\hline Total & $\mathbf{1 0 0}$ \\
\hline
\end{tabular}

Table.2 Effect of probiotic, prebiotic and synbiotic supplementation on dry matter intake in Murrah calves

\begin{tabular}{|c|c|c|c|c|}
\hline Days & \multicolumn{2}{|c|}{ Dry matter intake (kg) } & & \\
\hline & C & T-1 & T-2 & T-3 \\
\hline 0-15th Day & $50.68 \pm 0.96$ & $50.708 \pm 0.17$ & $50.05 \pm 0.43$ & $51.24 \pm 0.41$ \\
\hline 75-90th Day* $^{*}$ & $76.02 \pm 0.05^{\mathrm{c}}$ & $76.44 \pm 0.07^{\mathrm{b}}$ & $76.14 \pm 0.13^{\mathrm{bc}}$ & $76.86 \pm 0.17^{\mathrm{a}}$ \\
\hline Overall mean $^{\text {a }}$ & $63.77 \pm 4.31$ & $64.02 \pm 4.36$ & $63.65 \pm 4.43$ & $65.4 \pm 4.39$ \\
\hline
\end{tabular}

Means with different superscripts in a row differ significantly $(* \mathrm{P}<0.05)$.

Table.3 Effect of probiotic, prebiotic and synbiotic supplementation on body weight gain $(\mathrm{kg})$ in Murrah calves

\begin{tabular}{|c|c|c|c|c|}
\hline Days & \multicolumn{2}{|c|}{ Body weight gain $(\mathbf{k g})$} & & \\
\hline & $\mathbf{C}$ & $\mathbf{T - 1}$ & $\mathbf{T - 2}$ & $\mathbf{T - 3}$ \\
\hline 0-15th Day* $^{*}$ & $3.18 \pm 1.09^{\mathrm{b}}$ & $4.79 \pm 0.73^{\mathrm{ab}}$ & $5.88 \pm 0.36^{\mathrm{a}}$ & $6.38 \pm 0.57^{\mathrm{a}}$ \\
\hline 75-90th Day* $^{*}$ & $5.15 \pm 0.27^{\mathrm{b}}$ & $5.98 \pm 0.51^{\mathrm{ab}}$ & $6.54 \pm 0.24^{\mathrm{ab}}$ & $7.35 \pm 0.67^{\mathrm{a}}$ \\
\hline Overall mean $^{4}$ & $4.26 \pm 0.29$ & $5.26 \pm 0.18$ & $5.85 \pm 0.17$ & $6.81 \pm 0.15$ \\
\hline
\end{tabular}

Means with different superscripts in a row differ significantly $(* \mathrm{P}<0.05)$.

Table.4 Effect of probiotic, prebiotic and synbiotic supplementation on the average daily gain $(\mathrm{kg} /$ day) in Murrah calves

\begin{tabular}{|c|c|c|c|c|}
\hline Days & \multicolumn{4}{|c|}{ Average daily gain (kg/day) } \\
\hline & $\mathbf{C}$ & T-1 & $\mathbf{T - 2}$ & $\mathbf{T}-3$ \\
\hline $\mathbf{0 - 1 5}^{\text {th }}$ Day $^{*}$ & $0.227 \pm 0.07^{\mathrm{b}}$ & $0.342 \pm 0.05^{\mathrm{ab}}$ & $0.420 \pm 0.02^{\mathrm{ab}}$ & $0.455 \pm 0.04^{\mathrm{a}}$ \\
\hline $\mathbf{7 5 - 9 0}^{\text {th }}$ Day* $^{*}$ & $0.367 \pm 0.03^{\mathrm{b}}$ & $0.427 \pm 0.02^{\mathrm{ab}}$ & $0.467 \pm 0.02^{\mathrm{ab}}$ & $0.525 \pm 0.03^{\mathrm{a}}$ \\
\hline Overall mean $^{\mathrm{b}}$ & $0.303 \pm 0.02$ & $0.375 \pm 0.01$ & $0.418 \pm 0.01$ & $0.486 \pm 0.01$ \\
\hline
\end{tabular}

Means with different superscripts in a row differ significantly ( $* \mathrm{P}<0.05)$. 
Table.5 Effect of probiotic, prebiotic and synbiotic supplementation on feed conversion ratio (FCR) in Murrah calves

\begin{tabular}{|c|c|c|c|c|}
\hline Days & \multicolumn{4}{|c|}{ Feed conversion ratio(FCR) } \\
\hline & C & T-1 & T-2 & T-3 \\
\hline $\mathbf{0 - 1 5}^{\text {th }}$ Day** $^{\text {th }}$ & $15.93 \pm 0.16^{\mathrm{a}}$ & $10.58 \pm 0.18^{\mathrm{b}}$ & $8.63 \pm 0.27^{\mathrm{c}}$ & $8.03 \pm 0.06^{\mathrm{c}}$ \\
\hline $\mathbf{7 5 - 9 0}^{\text {th }}$ Day $^{*}$ & $14.76 \pm 0.23^{\mathrm{a}}$ & $12.78 \pm 0.46^{\mathrm{b}}$ & $11.64 \pm 0.27^{\mathrm{b}}$ & $10.46 \pm 0.24^{\mathrm{c}}$ \\
\hline Overall mean $^{\mathrm{b}}$ & $14.99 \pm 0.22$ & $12.09 \pm 0.45$ & $10.71 \pm 0.62$ & $9.41 \pm 0.44$ \\
\hline
\end{tabular}

Means with different superscripts in a row differ significantly $(* \mathrm{P}<0.05),(* * \mathrm{P}<0.01)$.

Table.6 Effect of probiotic, prebiotic and synbiotic supplementation on body condition score (BCS) in Murrah calves

\begin{tabular}{|c|c|c|c|c|}
\hline Days & \multicolumn{4}{|c|}{ Body condition score (BCS) } \\
\hline & $\mathbf{C}$ & T-1 & T- 2 & T-3 \\
\hline 0 $^{\text {th }}$ Day & $2.25 \pm 0.05$ & $2.28 \pm 0.04$ & $2.24 \pm 0.03$ & $2.28 \pm 0.03$ \\
\hline $\mathbf{9 0}^{\text {th }}$ Day & $2.56 \pm 0.16$ & $2.42 \pm 0.08$ & $2.37 \pm 0.10$ & $2.42 \pm 0.08$ \\
\hline Overall mean & $2.38 \pm 0.05$ & $2.34 \pm 0.02$ & $2.3 \pm 0.02$ & $2.33 \pm 0.02$ \\
\hline
\end{tabular}

Table.7 Effect of probiotic, prebiotic and synbiotic supplementation on the cost of feeding per kg weight gain ( ₹ ) in Murrah calves

\begin{tabular}{|c|c|c|c|c|}
\hline & \multicolumn{4}{c|}{ Cost of feeding ( ₹ ) } \\
\hline & C & T-1 & T-2 & T-3 \\
\hline $\begin{array}{c}\text { Mean cost of feeding } \\
\text { per calf for 90 days }\end{array}$ & $2146.62 \pm 3.53$ & $2568.17 \pm 6.40$ & $2379.93 \pm 2.87$ & $2446.4 \pm 7.35$ \\
\hline $\begin{array}{c}\text { Cost of feeding per } \\
\text { kg weight gain ( ₹ ) }\end{array}$ & $83.98 \pm 5.89$ & $81.42 \pm 4.23$ & $67.7 \pm 1.45$ & $59.79 \pm 6.97$ \\
\hline
\end{tabular}

Since, the difference in body weight $(\mathrm{kg})$ among the experimental calves was only less than $3 \mathrm{~kg}$, significant difference was not detected in BCS among the treatment and control group buffalo calves.

\section{Cost Per Kilogram Weight Gain}

The results on the effect of probiotic, prebiotic and synbiotic supplementation on cost $/ \mathrm{kg}$ weight gain in Murrah calves is presented in Table 7. The results showed an increase in the mean cost of feeding during entire experimental period. However, cost per $\mathrm{kg}$ weight gain (₹) was lower in T3 compared to $\mathrm{C}, \mathrm{T} 1$, and T2 and highest in C. Among the T1 and T2 groups, the cost per kg weight gain (₹ ) was higher in T1 compared to T2. Synbiotic supplementation in buffalo calves has reduced the cost per kg weight gain by (₹) 24, 22 and 8 compared to control, probiotic and prebiotic supplemented buffalo calves, respectively. Similar to the present findings, Dar et al., (2017) reported that probiotic and synbiotics are effective in increasing body weight gain and are less expensive than common feed supplements when compared in terms of cost per $\mathrm{kg}$ body weight gain in calves.

Combining probiotics and prebiotics are referred to as synbiotics that beneficially affects the host by improving the survival and 
establishment of live microbial dietary supplements in the gastrointestinal tract. The buffalo calves which were supplemented with dietary synbiotics had increased DMI, average daily gain, FCR which resulted into decreased cost of feeding per $\mathrm{kg}$ weight gain compared to either prebiotic or probiotic supplementation alone.

In view of the increased antibiotic resistance due to indiscriminate use of antimicrobials as growth promoters in calves, synbiotics may be used as alternate to antibiotics as growth promoters in calves. Synbiotics may be suggested as alternate to either probiotic or prebiotic for economic growth rate in calves.

\section{References}

Abdel-Fattah, F. A., \& Fararh, K. M. 2009. Effect of dietary supplementation of probiotic, prebiotic and synbiotic on performance, carcass characteristics, blood picture and some biochemical parameters in broiler chickens. Benha Vet. Med. J, 20, 9-23.

Abdel-Raheem, S. M., Abd-Allah, S. M., \& Hassanein, K. M. 2012. The effects of prebiotic, probiotic and synbiotic supplementation on intestinal microbial ecology and histomorphology of broiler chickens. International Journal for Agro Veterinary and Medical Sciences, 6(4), 277-289.

Abney, M. D. 2001. Effects of feeding directfed microbials and prebiotics on receiving calf performance, health, and fecal shedding of pathogens (Doctoral dissertation, Texas Tech University).

Alapati, A., Kapa, S. R., Jeepalyam, S., Rangappa, S. M. P., \& Yemireddy, K. R. 2010 Development of the body condition score system in Murrah buffaloes: validation through ultrasonic assessment of body fat reserves. Journal of veterinary science, 11(1), 1-8.
Awad, W., Ghareeb, K., \& Böhm, J. 2008. Intestinal structure and function of broiler chickens on diets supplemented with a synbiotic containing Enterococcus faecium and oligosaccharides. International Journal of Molecular Sciences, 9(11), 22052216.

Bandyopadhyay, A. K., Ray, P. R., \& Ghatak, P. K. 2003, January. Effective utilization of buffalo milk for manufacturing dairy products. Asian Buffalo Congress.

Berry, D., Macdonald, K. A., Penno, J. W., \& Roche, J. R. (2006). Association between body condition score and live weight in pasture-based HolsteinFriesian dairy cows.

Dar, A., Singh, S., Palod, J., Al Ain, K., Kumar, N., Khadda, B., \& Farooq, F. 2017. Effect of probiotic, prebiotic and Synbiotic on hematological parameters of crossbred calves. International Journal of Livestock Research, 7(4), 127-136.

Deng, Z. Y., Zhang, J. W., Li, J., Fan, Y. W., Cao, S. W., Huang, R. L.,... \& Li, T. J. 2007. Effect of polysaccharides of cassiae seeds on the intestinal microflora of piglets. Asia Pacific journal of clinical nutrition, 16, 143.

Fleige S W, Preibinger H H D, Mayer W P 2009 The immunmodulatory effect of lactulose on Entereococcus faecium-fed preruminant calves. Journal of Animal Science 87:1731-1738

Hasunuma, T., Kawashima, K., Nakayama, H., Murakami, T., Kanagawa, H., Ishii, T.,.. \& Kushibiki, S. 2011. Effect of cello oligosaccharide or synbiotic feeding on growth performance, fecal condition and hormone concentrations in Holstein calves. Animal science journal, 82(4), 543-548.

ICAR 2013 Nutrient Requirements of Cattle and Buffalo. Indian Council of Agricultural Research New Delhi. 
Jin, L. Z., Ho, Y. W., Abdullah, N., \& Jalaludin, S. 1997. Probiotics in poultry: modes of action. World's Poultry Science Journal, 53(4), 351-368.

Kong, X. F., Wu, G. Y., \& Yin, Y. L. 2011. Roles of phytochemicals in amino acid nutrition. Front. Biosci, 3, 372-384.

Kong, X. F., Yin, Y. L., He, Q. H., Yin, F. G., Liu, H. J., Li, T. J.,.. \& Xie, M. Y. 2009. Dietary supplementation with Chinese herbal powder enhances ileal digestibilities and serum concentrations of amino acids in young pigs. Amino acids, 37(4), 573-582.

Kumar, D. S., Prasad, J. R., \& Rao, E. R. 2011. Effect of dietary inclusion of yeast culture (Saccharomyces cerevisiae) on growth performance of graded Murrah buffalo bull calves. Buffalo Bulletin, 30(1), 63-66.

Lesmeister, K. E., Heinrichs, A. J., \& Gabler, M. T. 2004. Effects of supplemental yeast (Saccharomyces cerevisiae) culture on rumen development, growth characteristics, and blood parameters in neonatal dairy calves. Journal of dairy science, 87(6), 1832-1839.

Li, L. L., Hou, Z. P., Li, T. J., Wu, G. Y., Huang, R. L., Tang, Z. R., \& Pan, E. 2008. Effects of dietary probiotic supplementation on ileal digestibility of nutrients and growth performance in 1-to 42-day-old broilers. Journal of the Science of Food and Agriculture, 88(1), 35-42.

Moarrab, A., Ghoorchi, T., Ramezanpour, S., Ganji, F., \& Koochakzadeh, A. R. 2016. Effect of synbiotic on performance, intestinal morphology, fecal microbial population and blood metabolites of suckling lambs. Iranian Journal of Applied Animal Science, 6(3), 621-628.

Okamoto, Y., Inoue, A., Miyatake, K., Ogihara, K., Shigemasa, Y., \& Minami, S. 2003. Effects of chitin/chitosan and their oligomers/monomers on migrations of macrophages. Macromolecular Bioscience, 3(10), 587-590.

Resali D P 2000 Bulletin of the FAO InterRegional cooperative Research Network on Buffalo. Europe-Near Estate, 14: 610 .

Roodposhti, P. M., \& Dabiri, N. 2012. Effects of probiotic and prebiotic on average daily gain, fecal shedding of Escherichia coli, and immune system status in newborn female calves. AsianAustralasian journal of animal sciences, 25(9), 1255.

Sadrsaniya, D. A., Raval, A. P., Bhagwat, S. R., \& Nageshwar, A. 2015. Effects of probiotics supplementation on growth and nutrient utilization in female Mehsana buffalo calves. Indian Vet. J, 92(9), 20-22.

SPSS version (15.01) 2006, Chicago. IL: SPSS Inc. 2006.

Timmerman, H. M., Mulder, L., Everts, H., Van Espen, D. C., Van Der Wal, E., Klaassen, G.,... \& Beynen, A. C. 2005. Health and growth of veal calves fed milk replacers with or without probiotics. Journal of Dairy Science, $88(6), 2154-2165$.

\section{How to cite this article:}

Sri Lekha, M., Ch. Venkata Seshaiah, P. Ashalatha and Raja Kishore, K. 2021. Effect of Probiotic, Prebiotic and Synbiotic Supplementation on Growth Performance in Murrah Buffalo Calves. Int.J.Curr.Microbiol.App.Sci. 10(05): 280-287. doi: https://doi.org/10.20546/ijcmas.2021.1005.035 